\title{
Research on Training and Developing Employees
}

\author{
Peng Cui \\ School of Business management, Tonghua Normal University \\ Tonghua, China \\ dbcy9999@163.com
}

\begin{abstract}
This paper is devoted to the issue of ongoing training and development of employees. Analysis, techniques, purposes, and evaluation needed are all covered. Additionally, the paper points out the importance of new employee orientation and lists some of the important things to cover during that process.
\end{abstract}

Keywords-Employee orientation; Training; On-the-job training; Job instruction training; Succession planning

\section{MANAGING CAREERS}

This paper first gives good advice and tools for managing careers. It also covers the issue of building communications with employees through guaranteed fair treatment programs and employee discipline. Proper handling of dismissals and separations, including retirement are explored. While today many employees are retiring earlier, many experts believe that the next generation will have to retire later in order to continue to fund the retirement of those retiring now. Social Security has already increased the ages at which future generations will be eligible for benefits. New employees can suffer from a significant amount of anxiety during the first few days on the job as they find themselves in an environment and culture that they are not familiar with. Those with little job experience may find it especially difficult without an orientation since they have little other experience on which to base their expectations. A well-developed orientation program will socialize new employees into important organizational values, whereby their chances of easing smoothly into the organization are improved.

The individual must accept responsibility for his/her own career; assess his/her own interests, skill, and values; and take the steps required to ensure a happy and fulfilling career. Employee Career Development - There are several things that the manager can do to support his or her subordinates' career development needs. Provide Realistic Job Previews that describe both the attractions and possible pitfalls to help minimize reality shock and improve long-term performance. Provide Mentoring Opportunities - Mentoring can have positive effects on employees' careers, including faster promotions and salary progression and reduced anxiety; but it can be a two-edged sword. Making Promotion Decisions Promotions usually provide opportunities to reward the exceptional performance of tested and loyal employees. However, unfairness, arbitrariness, or secrecy can diminish the effectiveness of the promotion process for all concerned. The New Psychological Contract - Yesterday's contract was "do your best and be loyal to us and we will take care of your career." Today it is "do your best and be loyal to us as long as you are here, and we'll provide you with the developmental opportunities you'll need to move on and have a successful career." The New Career Management System - By implementing a career management system, the Hotel Paris was able to noticeably improve various measures of employee commitment and guest services.

\section{ORIENTING EMPLOYEES}

What are some typical on-the-job training techniques? What do you think are some of the main drawbacks of relying on informal on-the-job training for breaking new employees into their jobs? New employee orientation [1-3] has been shown to have measurable and positive effects on employee retention and satisfaction. In spite of this, many organizations do not have a formalized orientation process and each employee gets a different orientation to the organization. For those students who have been employed, it may be useful to discuss their experiences and frustrations or satisfaction with orientations. Employee orientation programs provide new employees with the basic background information required to perform their jobs satisfactorily. Orientation programs today are moving away from routine discussion of company rules to emphasizing the company's mission and the employee's role in that mission, onboarding them early as a key member of the team. A well-thought-out orientation program is essential for all new employees, whether they have experience or not." Explain why you agree or disagree with this statement. New employees can suffer from a significant amount of anxiety during the first few days on the job as they find themselves in an environment and culture that they are not familiar with. Those with little job experience may find it especially difficult without an orientation since they have little other experience on which to base their expectations. A well-developed orientation program will socialize new employees into important organizational values, whereby their chances of easing smoothly into the organization are improved.

\section{THE TRAINING PROCESS}

What do you think of Apex's training process? Could it help to explain why employees "do things their way" and if so, how? There is a weak accountability system. The person assigned to perform training is likely to have very low motivation (a departing employee). With no formal descriptions the trainer will teach "their way" of accomplishing tasks. There is no training documentation. One receives training in "how to train." There are no outcome measures to determine if the training was successful. 
A. The Strategic Context of Training - Training refers to the methods used to give new or present employees the skills they need to perform their jobs. Training today plays a key role in the performance management process, which is a key process for employers to ensure employees are working toward organizational goals. Overall, training has a fairly impressive record of influencing organizational effectiveness, scoring higher than appraisal and feedback, and just below goal setting in its effect on productivity.

B. The Five Step Training and Development Process - 1) needs analysis; 2) instructional design; 3) validation; 4) implement the program; and 5) evaluation and follow-up.

\section{Training, Learning, and Motivation}

1. Make Learning Meaningful - Material that is meaningful is usually easier for trainees to understand and remember.

2. Make Skills Transfer Easy - Make skills and behaviors easy to transfer from the training site to the job site.

3. Motivate the Learner - Provide as much realistic practice as possible; reinforce correct responses immediately; letting trainees pace themselves; creating a perceived

D. Analyzing Training Needs - Two main ways to identify training needs are: task analysis (an analysis of the job's requirements) and performance analysis (an analysis to verify if there is a performance deficiency).

E. Task Analysis: Assessing New Employees' Training Needs - A task analysis can be use to determine the training needs of new employees. A task analysis record form can also be used. It contains the following information: task list; when and how often performed; quantity, quality performance standards; conditions under which performed; skills or knowledge required; and where best learned.

F. Performance Analysis: Assessing Current Employees' Training Needs - There are several methods that can be used to identify an employee's training needs, including: supervisor, peer, self, and 360-degree performance reviews; job-related performance data; observation by supervisors or other specialists; interviews with the employee or his/her supervisor; tests of things like job knowledge, skills, and attendance; attitude surveys; individual employee daily diaries; and assessment centers.

\section{TRAINING METHODS}

What role do job descriptions play in training? Job descriptions set the boundaries of jobs in terms of required knowledge and skills. By understanding the job description, a trainer can define the learning requirements for a new or transitioning employee.

A. On-the-Job Training (OJT) [4-7] - means having a person learn a job by actually doing it, and involves the following: preparing the learner; presenting the operation; doing a tryout; and follow-up.

B. Apprenticeship Training - is a structured process by which people become skilled workers through a combination of classroom instruction and on-the-job training.
C. Informal Learning - involves learning through day-today unplanned interactions between the new worker and his/her colleagues.

D. Job Instruction Training - refers to teaching a new employee the logical sequence of steps in a job step-by-step.

E. Lectures - quick and simple way to provide knowledge to large groups.

F. Programmed Learning - is a step-by-step self-learning method: 1) presenting questions, facts, or problems to the learner; 2) allowing the person to respond; and 3) providing feedback on the accuracy of the answers.

G. Literacy Training Techniques - Companies are responding the functional illiteracy by testing job candidates' basic skills, and setting up basic skills and literacy programs.

The New Workplace: Diversity Training Program Diversity training aims to create better cross-cultural sensitivity, with the aim of fostering more harmonious working relationships among a firm's employees.

H. Audiovisual Based Training - Tools include: films, PowerPoint presentations, video conferencing, audiotapes, and videotapes.

I. Simulated Training - is a method in which trainees learn on the actual or simulated equipment they will use on the job, but are actually trained off-the job.

J. Computer-Based Training - is where the trainee uses computer-based and/or DVD systems to increase his/her knowledge or skills. CBT programs have real advantages including reducing learning time, cost effectiveness once designed and produced, instructional consistency, mastery of learning, increased retention, and increased trainee motivation.

K. Electronic Performance Support Systems (EPSS) - are sets of computerized tools and displays that effectively automate and integrate training, documentation, and phone support, thus enabling individuals to provide support that's faster, cheaper, and more effective than the traditional methods.

L. Distance and Internet-Based Training - Distance learning methods include traditional paper-and-pencil correspondence courses, as well as teletraining, videoconferencing, and Internet-based classes.

1. Teletraining - where a trainer in a central location teaches groups of employees at remote locations via television hookups.

2. Videoconferencing - allows people in one location to communicate live via a combination of audio and visual equipment with people in different locations-another city or country or with groups in several cities.

3. Training via the Internet - Internet based learning programs are increasingly popular. Some companies simply let their employees take online courses offered by online course providers while others use their intranets to facilitate computerbased training.

Improving Productivity Through HRIS: Learning Portals and Beyond. Learning Portals, also called Enterprise 
Information Portals (EIPs), like Yahoo! And other windows to the Internet, are enabling some categories of a firm's employees to access all the corporate applications they need, like industry news and competitive data, or tools to analyze data. There are also business to consumer (B2C) portals and business-to-business (B2B) portals.

Management Development is any attempt to improve managerial performance by imparting knowledge, changing attitudes, or increasing skills. The general management development process consists of (1) assessing the company's strategic needs (2) appraising the managers' current performance and (3) developing the managers. Succession planning [8] is part of this process, and is the process through which a company plans for and fills senior level openings.

A. Managerial On-The-Job Training methods include: job rotation; coaching/ understudy approach; and action learning.

1. Job Rotation - moving management trainees from department to department to broaden their understanding of all parts of the business.

2. Coaching/Understudy Approach - where a trainee works directly with a senior manager or with the person he/she is to replace, and the latter is responsible for coaching the trainee.

3. Action Learning - programs give managers and others released time to work full-time on projects to analyze and solve problems in departments other than their own.

Research Insight - Some research suggest that in addition to shattering the glass ceiling for women for equity sake, women may make better managers than men these days.

B. Off-the-Job Management Training and Development Techniques

1. The Case Study Method - presents a trainee with a written description of an organizational problem.

2. Management Games - computerized management games allow for the trainees to be involved.

3. Outside Seminars - offered by many companies and universities.

4. University-Related Programs provide executive education and continuing education programs in leadership, supervision, and the like.

5. Role Playing is aimed at creating a realistic situation and then having the trainee assume the parts (roles) of specific persons in that situation.

6. Behavior Modeling involves showing the trainee the correct way to do something, letting the trainee practice the correct way, and giving the trainee feedback on his/her performance.

7. Corporate Universities and In-House Development Centers are being established by many companies to expose prospective managers to realistic exercises to develop improved management skills.

8. Executive Coaches are being used by firms to improve their top managers' effectiveness. An executive coach is an outside consultant who questions the executive's boss, peers, subordinates, and sometimes, family, in order to identify strengths and weaknesses, and to counsel the executive so he or she can capitalize on those strengths and overcome the weaknesses.

\section{Managing ORganizational Change And DEVELOPMENT}

A. What to Change - When organizations are faced with the need to manage change, there are five different aspects that can be targeted including strategy, culture, structure, technologies and attitudes and skills.

B. Overcoming Resistance to Change: Lewin's Change Process - The most difficult part o implementing an organizational change is overcoming employees' resistance to it. Psychologist Kurt Lewin formulated a classic explanation of how to implement change in the face of resistance. His change process consists of three steps: 1) unfreezing; 2) moving; 3) refreezing.

C. How to Lead the Change: A 10 Step Change Process The ten steps outlined here are 1) establish a sense of urgency; 2) mobilize commitment through joint diagnosis of problem 3) Create a guiding coalition; 4) develop a shared vision; 5) communicate the vision; 6) help employees make the change; 7 ) generate short term wins; 8) consolidate gains and produce more change 9) anchor the new ways of doing things in the company culture; 10) monitor progress and adjust the vision as required.

D. Using Organizational Development - Organizational Development is a special approach to organizational change in which the employees themselves formulate the change that required and implement it, often with the assistance of a trained consultant. OD has several distinguishing characteristics, including action research; applied behavioral science knowledge to improve the organization's effectiveness; its ability to change attitudes, values and beliefs of employees so that they can implement the technical, procedural, or structural changes needed; and it changes the organization in a particular direction

1. You're the supervisor of a group of employees whose task is to assemble disk drives that go into computers. You find that quality is not what it should be and that many of your group's devices have to be brought back and reworked; your boss says that "You'd better start doing a better job of training your workers." A) What are some of the "staffing factors" that could be contributing to this problem? B) Explain how you would go about assessing whether it is in fact a training problem. Have students brainstorm the potential factors other than training that could be the root cause of this problem. Make the point that often, people will immediately point to training as the issue, when in fact there are other factors at play that are impacting performance.

2. Pick out some task with which you are familiar mowing the lawn, tuning a car - and develop a job instruction training [9-10] sheet for it. There is an example of a job instruction training sheet for operating a large motorized paper 
cutter. Students should be able to put the task they select into the format given.

3. Working individually or in groups, you are to develop a short programmed learning program on the subject "Guidelines for Giving a More Effective Lecture." Students should use the guidelines listed in the programmed learning section of the paper, but should not forget that this assignment is not just listing guidelines. They are to develop a programmed learning that 1) presents questions, facts, or problems to the learner, 2) allows the person to respond, and 3) provides feedback to the learner on the accuracy of his or her answers.

4. Working individually or in groups, use the phone or the web to contact a provider of management development seminars such as the American Management Association. Obtain copies of their recent listings of seminar offerings. At what levels of managers do they aim their seminar offerings? What seems to be the most popular types of development programs? Why do you think that's the case? Depending on the provider contacted, the results of this exercise will vary. It would be a good idea to assign different groups or individuals to different providers to assure that you get a variety of responses. It may be useful to have a class discussion about the differences that they found.

5. Working individually or in groups, develop several examples to illustrate how a professor teaching human resource management could use at least four of the techniques described in this paper in teaching his or her HR course. Student results will again vary. Look for examples to be well thought out and to represent the guidelines given in the appropriate sections on traditional training techniques.

6. Working individually or in groups, develop an orientation program for high school graduates entering your university as freshmen. The students should refer to the section on why orientation is important in the paper. They should also create an orientation checklist.

7. The HRCI "Test Specifications" appendix at the end of this book lists the knowledge someone studying for the HRCI certification exam needs to know in each area of human resource management (such as in Strategic Management, Workforce Planning, and Human Resource Development). In groups of 4-5 students, do four things: (1) review that appendix now; (2) identify the material in this chapter that relates to the required knowledge the appendix lists; (3) write four multiple choice exam questions on this material that you believe would be suitable for inclusion in the HRCI exam; and (4) if time permits, have someone from your team post your team's questions in front of the class, so the students in other teams can take others' exam questions. Material covered in this paper relevant to the HRCI exam would include succession planning, needs analysis, development, implementation and evaluation of training programs, development, raining methods, programs and techniques, instructional methods and program delivery, implementation and evaluation of programs to assess employees' potential for growth and development in the organization, change management programs and activities, organizational development theories and applications, employee involvement strategies.

\section{SUMMARY}

Designing the Study - The evaluation process of choice is controlled by experimentation, which uses both a training group and a control group (that receives no training) to assess their before and after performance in order to determine the extent to which performance in the training group resulted from the training itself rather than some organization-wide change. The employee must understand that it is their role to take charge of their own career development. The manager should support the employee's career development needs and schedule regular performance appraisals. The employer's role depends on how long the employee has been with the organization, but should include providing a process and a structure to develop their careers. These could include mentoring programs, increasing opportunities for networking and interaction, providing realistic job previews, providing challenging first jobs, and implementing career-oriented appraisals.

\section{ACKNOWLEDGMENT}

This research was supported by Research Foundation of Education Bureau of Jilin Province (Grant No.JJKH20170444SK).

\section{REFERENCES}

[1] Jose M. Acevedo; George B. Yancey, Assessing new employee orientation programs, Journal of Workplace Learning, 2011.

[2] Sapna Popli; Irfan A Rizvi, Exploring the relationship between service orientation, employee engagement and perceived leadership style: a study of managers in the private service sector organizations in India, Journal of Services Marketing, 2015, pp.59-70.

[3] Gordon Liu; Wai Wai Ko; Chris Chapleo, Managing employee attention and internal branding, Journal of Business Research, 2017.

[4] Jinqi Jiang; Guangsheng Zhang; Diming Qi; Mi Zhou, Can on-the-job training stabilize employment among rural migrant workers?, 2016,pp.498-515.

[5] Rita K Almeida, Marta Faria, The wage returns to on-the-job training: evidence from matched employer-employee data, IZA Journal of Labor \& Development, 2014, Vol.3 (1), pp.1-33.

[6] Kosovka Ognjenović, On-the-Job Training and Human Resource Management: How to Improve Competitive Advantage of an Organization?, Organization, pp. 740-741, 2015.

[7] Ronald L. Jacobs; Mohammad Jaseem Bu-Rahmah, Developing employee expertise through structured on-the-job training (S-OJT): an introduction to this training approach and the KNPC experience, Industrial and Commercial Training, pp. 75-84, 2012.

[8] E Michael Donner; Daniel Gridley; Sidney Ulreich; Edward I. Bluth, Succession Planning and Management - The Backbone of the Radiology Group's Future, Journal of the American College of Radiology, 2016.

[9] Bartosz Misiurek; Tomasz Koch, Teaching formula of the training for operators on effective application of lean management tools, Management and Production Engineering Review, pp. 21-27, 2014.

[10] J. Clerk Maxwell, From the Editor, The Turkish Online Journal of Distance Education, 2006. 